Revista Iberoamericana. Vol. LXII, Núms. 176-177, Julio-Diciembre 1996; 745-766

\title{
TRÁFICO DE IDENTIDADES: MUJERES, CULTURA Y POLÍTICA DE REPRESENTACIÓN EN LA ERA NEOLIBERAL
}

\author{
POR \\ Francine MASIELlo \\ University of California, Berkeley
}

Los vecinos proclaman que es indispensable custodiar el destino de Occidente. Dime ¿acaso no has pensado que Occidente podría estar en la dirección opuesta?

Diamela Eltit, Los vigilantes

En las pinturas y collages de Liliana Porter, artista visual argentina residente en Nueva York, uno entra en un mundo de recuerdos del kitsch revolucionario, un mundo donde las relaciones entre la obra original y su copia, entre la autenticidad y la falsificación, ocupan un lugar importante. Su trabajo se basa en los íconos de la cultura de masas contemporáneaartículos de Disney, juguetes de baratillo, vulgares figuras de cerámica, el conjunto de los cuales forma una naturaleza muerta de nuestra experiencia global común. En "Mutaciones con platito del Che" (1994), una litografia con collage fotográfico, Porter nos invita a especular sobre las intersecciones de la cultura postmoderna. A lo largo de un plato estampado con una calcomanía del Che Guevara, ella coloca un Mickey Mouse de plástico, una carta extraída de la baraja mejicana de la lotería, un busto de San Gregorio, el popular santo venezolano y una postal con la imagen de una mujer renacentista. Estas imágenes recicladas nos ofrecen una breve visión del imaginario cultural contemporáneo de las Américas del Norte y del Sur. Al estar formuladas mediante la reproducción en serie, las copias evitan cualquier reconocimiento del momento creativo original. Por lo tanto, niegan toda escala jerárquica en el supuesto esquema de valores occidentales.

Sin embargo, el título del collage de Porter se refiere a la gran figura revolucionaria de Latinoamérica, el Che Guevara, cuyo retrato es colocado en el centro de un plato de postre y reflejado en un espejo de tocador. La doble representación del héroe apunta a la repetición hecha posible por la tecnología, pero, sobre todo, el espejo y el plato evocan un ambiente doméstico claramente identificado con el consumismo femenino. El Che Guevara encuentra así un lugar entre los cachivaches caseros, como una baratija más. En este mundo de simulacros, donde el arte culto y el popular se entrecruzan, incluso las relaciones domésticas quedan definidas por la producción en serie. El mercado global nos condiciona para percibir las diferencias por su exotismo, como si formara parte de los gustos eclécticos del consumidor. En el proceso, se pierde toda experiencia histórica; más bien, se suprime la historia a través del comercio del kitsch.

Porternos deja contemplando los atavíos de la domesticidad femenina que va tácitamente conectando estas imágenes extraídas del comercio global. En este sentido, nos lleva a 
preguntarnos sobre el centro femenino ausente en esta reunión de objetos. ¿Cómo circula la imaginación femenina en el tráfico global? ¿Cómo se debaten las mujeres entre los productos de la sociedad de masas y los valores asociados con el arte culto y la estética? Y, finalmente, ¿cómo emerge a la superficie la invisibilidad femenina, haciéndose visible en la sintaxis de intercambios Norte/Sur? En las páginas a seguir, quiero discutir las maneras en que las identidades de género se insertan en el panorama de las relaciones culturales Norte-Sur. Sobre todo despues de la Guerra Fría, la identidad de género circula libremente a través de las fronteras internacionales como parte de una economía conceptual manejada por las universidades, los museos y los medios de comunicación, y, de manera más obvia, como parte de una economía de mercado mantenida por un capital global. La identidad de género es a menudo el vehículo oculto de transporte para un proyecto narrativo en particular, el cual da forma a los gustos de los consumidores transnacionales viajando entre el norte y el sur.

Tal y como queda determinado por el Norte, se espera de los hombres y mujeres latinoamericanos que actúen según unos deseos regulados, que ofrezcan una narrativa de identidad propia que se adapte fácilmente al circuito internacional. Teniendo esto en cuenta, podríamos hablar de ciertos tipos de nostalgia que gobiernan las fantasías Norte/Sur, del deseo de recuperar la era de estabilidad que precede al proyecto neoliberal. ${ }^{1}$ Este deseo toma varias formas. En su versión conservadora, las mujeres se siguen identificando con el sentimentalismo y con el terreno de los "sentimientos" en general, lo cual le crea a la comunidad la ilusión de estar evitando las enormes injusticias del mercado. La retórica de los valores familiares mantiene esta percepción, y también asocia una imagen de mujeres y hombres de buen hacer con el ideal de ciudadanía deseado. En cambio, dentro de un contexto progresista, hombres y mujeres son programados para otro tipo de respuestas: se esperaría, por ejemplo, que las mujeres opusieran resistencia al nacionalismo patriarcal, o que las intervenciones marcadas por las identidades de género perturbaran las relaciones convencionales de familia y Estado.

El paradigma de los sexos nos permite, pues, localizar cambios dentro de la política de representación como una cuestión tanto de inclusión democrática como de forma estética. Me gustaría examinar aquí los tipos de ficción que circulan entre el Nortey el Sur, concentrándome en la intervención de la identidad de género en las ciencias sociales y en la cultura literaria. En éstas se destacan una serie de estrategias narrativas, tanto en la ficción como en el campo teórico, pero éstas además nos hacen recordar el papel crucial de los mediadores de la cultura dentro de la corriente Norte/Sur.

\section{LOS TERRENOS TEORIZABLES}

En el debate sobre la representación en ambas Américas, el relativismo cultural determina las jerarquías del conocimiento, normalmente mediante la aceptación de la teoría anglo-europea como una fuente unitaria de ideas. ${ }^{2}$ No sólo es el Norte percibido como el

\footnotetext{
' Como siempre, les estoy agradecida a Gwen Kirkpatrick, Mary Louise Pratt, Francesca Miller y Marta Morello-Frosch, por sus conversaciones conmigo, ya que éstas me han hecho ver la importancia de la nostalgia y el heroísmo como elementos de la experiencia neoliberal actual.

${ }^{2}$ Ferman (1993) y S. P. Mohanty (1989) han estudiado en profundidad la cuestión del relativismo cultural, y reconozco la influencia de sus estudios en estas páginas. El término "traveling theory", acuñado por Edward Said, también ha influido en mis reflexiones.
} 
depositario de la teoría, que supuestamente alberga todo pensamiento universal abstracto, sino que también el Norte impone un estilo de autodefinición que es copiado con avidez en el resto del mundo. Carolyn Porter (1994), por ejemplo, ha "descubierto" recientemente los beneficios de un estudio comparativo Norte/Sur, afirmando que éste amplia el enfoque de los proyectos "americanistas" tal y como se organizan desde los departamentos de literatura inglesa de las universidades norteamericanas. Su estrategia consiste en construir un marco de discusión más extenso para explicar las culturas de los dos hemisferios desde la perspectiva de los Estados Unidos; este proceso acusa, sin embargo, una tendencia a "fantasear al otro", como un gesto de reconocimiento del Sur sin ningún compromiso estable con los proyectos políticos o estéticos que Latinoamérica pueda ofrecer. También se da por supuesto que los intelectuales del Sur nunca habían considerado esta problemática comparativa antes. ${ }^{3}$

En el viaje de las ideas, a menudo se propone una ruta sólo de ida. Hace años, Jean Franco nos alertó de los peligros de la dominación metropolitana sobre la teoría y de los mecanismos que ésta implica: "1. exclusión-el Tercer Mundo es irrelevante para la teoría; 2. discriminación-el Tercer Mundo es irracional y por lo tanto su saber queda subordinado al saber racional producido por la metrópolis; y 3. reconocimiento - el Tercer Mundo sólo es visto como el lugar de lo instintivo" (504). El problema está aún por resolver; de hecho, la insistencia en la inferioridad latinoamericana en el campo de la teoría sigue penetrando la imaginación de los críticos a ambos lados de la frontera. En consecuencia, las discusiones sobre la atrasada modernidad de Latinoamérica se han instalado sobre el eje Norte-Sur en virtud de la influencia de la teoría producida en el Norte. De la misma manera, los debates sobre el postmodernismo latinoamericano, e incluso los estudios culturales latinoamericanos, han partido de la premisa de que los paradigmas estadounidenses proporcionan el estímulo inicial necesario para la apertura de debates en el Sur. ${ }^{4}$ Como resultado, hasta algunas de las mentes más lúcidas de Latinoamérica siguen afirmando que la era de la teoría aún no ha llegado al Sur.

Si tenemos en cuenta diversas opiniones del eje Norte/Sur, actualmente se considera que las ideologías han fracasado en Latinoamérica, que la era de las utopías ha pasado (Castañeda); que los movimientos sociales han perdido su imperativo, debido a la ausencia de visiones teóricas de largo alcance (Moreiras); incluso la literatura latinoamericana como actividad cultural es vista al borde de la extinción - en tanto en cuanto la literatura es un recordatorio del pasado colonial, ésta constituye una institución arcaica y sin sentido (Beverley). En estos casos, a Latinoamérica se le acusa de una incapacidad para teorizar; los críticos comentan que Latinoamérica manifiesta una deficiencia a la hora de rescatar la acción por medio de paradigmas de pensamiento abstracto. Sólo hay que tener en cuenta el caso de la obra de gran éxito Utopia Unarmed (1993), de Jorge Castañeda, donde el autor atribuye los fracasos de Latinoamérica a los proyectos mal organizados de la izquierda. Figuras tales como Mario

\footnotetext{
${ }^{3}$ Desde los primeros años de la independencia, los intelectuales latinoamericanos han sido siempre conscientes de la división Norte/Sur, y han tratado de encontrar modelos teóricos que los incluyeran como sujetos activos. A este respecto, sólo hay que tener en cuenta, por ejemplo, el destacado caso de Sarmiento.

${ }^{4}$ George Yúdice (1994) ha escrito una sugestiva crítica del proceso por el cual los paradigmas de minorías culturales, formulados como tales en el medio académico estadounidense bajo la rúbrica de "estudios culturales", no han sido bien recibidos en Latinoamérica.
} 
Firmenich, Cayetano Carpio y Pascal Allende son vistos como inmaduros bromistas que precipitaron la caída de una teoría histórica del "gran hombre" en la década del activismo de los setenta. Los héroes del ayer son reducidos a un cuadro de kitsch, como recordatorios de un espíritu equivocado que debería olvidarse.

Con juegos de lógica como éste, parece como si los latinoamericanos dependieran del consejo de la metrópolis, haciendo así destacar el paradigma neoliberal como el camino más viable para los noventa. Como una hoja de papel plegada, el mapa se dobla por la frontera, creando manchas de tinta idénticas a cada lado de la división hemisférica. La diferencia, a medida que prolifera, es contenida como una estampación del pensamiento post-original. ${ }^{5}$

En White Noise, una famosa novela norteamericana sobre la vida académica, del escritor Don DeLillo, uno de los personajes, tras un desastre nuclear, dirige la siguiente pregunta al equipo de rescate: “¿Están diciéndome que ustedes vieron la oportunidad de usar el suceso real para ensayar el simulacro?”(139). Me pregunto si la representación de Latinoamérica por parte del Norte constituye un intento de montar simulaciones, de quitarle importancia a la experiencia vital para cultivar modelos abstractos. En Donde van a morir los elefantes (1995), otra novela sobre la vida académica en los EE.UU., esta vez de un latinoamericano, el personaje de José Donoso se pregunta acerca de la visión de los Estados Unidos en ojos extranjeros: “¿Cómo nos verán a nosotros? ... ¿Qué pueden entender de nuestra visión de lo que es ridículo o grotesco o admirable? Me figuro que para ellos somos sólo un reflejo, una realidad virtual" (79). Para Donoso, la experiencia real de una cultura se convierte en un campo de pruebas para la teoría de la otra cultura, la cual termina adquiriendo vida propia. A su vez, esta última es exportada de vuelta al país de origen con el objeto de determinar las vidas de sus habitantes. Como queriendo contrarrestar las generalizaciones del yanqui nacionalista, un personaje chileno de la misma novela observa: "Son los yanquis quienes nos exigen que seamos violentos y sexuales y pobres, que acusemos y señalemos con el dedo al culpable. $Y$ si no somos así, no nos quieren, porque no podemos ser objeto de ninguna policy de salvataje" (91).

Partiendo de este enredo de cuestiones críticas, otros intelectuales intentan devolver el papel de agenciamiento a los sujetos latinoamericanos, mediante estrategias alternativas, si bien a menudo insuficientes, de representación. Este proceso da como resultado historias de salvación que anuncian triunfos latinoamericanos; más que una nueva utopía, estas narrativas

\footnotetext{
${ }^{5}$ Algunos defensores del postmodernismo ven este impulso como una manera de descentrar todo pensamiento hegemónico, al afirmar que en estas condiciones incluso las sociedades marginales tienen la oportunidad de borrar la distinción entre la expresión popular y la culta, entre la teoría metropolitana y sus traducciones periféricas. Por medio del intercambio global de imágenes, a través de redes de comunicación y nuevas tecnologías, todas las mentes son afectadas por un único sistema, y el territorio queda nivelado. De este modo, todos los miembros de una sociedad global pueden copiar las imágenes que ven; lo cual, por otro lado, les facilita una máscara de carnaval con la que desafiar formas e identidades fijas. En este juego de adivinanzas con rostros de quita y pon, donde las copias se valoran más que el original, las culturas periféricas encuentran un lugar competitivo dentro de la dinámica del nuevo sistema mundial. Abandonan el pasado histórico para centrarse en un mundo prefabricado libre del peso de la polémica y el debate. Este tipo de análisis parece asumir que todo el mundo ha olvidado que este proyecto está dirigido por los líderes de empresas multinacionales.
} 
intentan ofrecer continuamente nuevas categorías de identidad mediante instrumentos y mecanismos de investigación que a menudo invaden el terreno de la ficción. ${ }^{6}$

Un tipo de heroísmo narrativo en particular es atribuido a los sujetos latinoamericanos, e incluso penetra los marcos teóricos que se están desarrollando en Latinoamérica. Rosalba Campra observa que el imperativo mimético de copiar al Norte fue una condición importante de la existencia latinoamericana: "La conducta mimética aparece entonces como la única existente; la máscara como el único rostro aceptable" (Campra 18). Esto forma la base de una literatura de dependencia (lo cual es el foco central del libro de Campra), pero proporciona una máscara que protege contra cualquier acercamiento a un yo auténtico. Así, aparecen una serie de sucedáneos que contribuyen a lo que Campra describe como "arquetipos de marginalidad" (27): indios, gauchos y emigrantes, forman el celebrado reparto de personajes latinoamericanos. Estas figuras promueven un cierto tipo de narrativa, un melodrama de rebelión y catarsis; un romance de supervivencia y triunfo. Al proporcionar una fantasía optimista de resistencia, los prototipos marginales de Latinoamérica siguen disfrutando de gran popularidad, restándole importancia a los fracasos que caracterizaron el activismo de izquierda de los últimos años. Las mujeres latinoamericanas se han desplazado ahora al centro de este heroísmo narrativo, prometiendo esperanzas de rendención social mediante una micropolítica de cambio. Esto conlleva una teorización contingente propia, y promueve unas formas de identidad que exaltan los márgenes de la sociedad.

\section{LAS MEDIADORES CULTURALES: ESPECULANDO CON LA IDENTIDAD FEMENINA}

Norma Alarcón ha observado que la teoría feminista anglosajona enfatiza el triunfo individual mientras que los "nativos" del tercer mundo son agrupados teóricamente como sujetos colectivos de proyectos racistas o colonialistas (357). Así, las mujeres de fuera de la metrópolis no tienen acceso a una historia propia; agrupadas de manera anónima o colectiva, están obligadas a representar a sus comunidades, pero no a demostrar sus méritos individuales. De este modo, aduce Alarcón, las mujeres subalternas son siempre ejemplos de una causa en particular.

Algunos libros publicados recientemente por académicas norteamericanas le dan un giro distinto a este problema. Éstos nos muestran cómo las mujeres latinoamericanas de hecho sí ejemplifican valores individuales, pero a menudo en respuesta a un proyecto narrativo cuyas leyes operativas han sido establecidas por el Norte. Esto es evidente, por ejemplo, en recientes estudios etnográficos y literarios, relativos a la cultura de la mujer, los cuales celebran los triunfos de las mujeres latinoamericanas así como las buenas intenciones de las mediadores culturales que observan su progreso. El resultado, en los años noventa, es un nuevo estilo de narrativa muy consciente de sus objetivos, que nos obliga a pensar en el poder de la mediación como discurso cultural.

\footnotetext{
${ }^{6}$ Aunque su análisis de este fenómeno difiere del mío, Gwen Kirkpatrick presenta un lúcido estudio de las ficciones utópicas producidas por el feminismo; en concreto, ésta observa el reciente interés prestado a la marginalidad: "Llegan a nuestra atención las mujeres de la esfera pública por sus desvíos, no por su heroicidad, su capacidad, o simplemente por la persistencia por sobrevivir" (47).
} 
Podemos considerar, por ejemplo, la publicación de Lynn Stephen del "testimonio" de una mujer salvadoreña, María Teresa Tula. La editora explica que las experiencias de su sujeto testimonial la han "transformado en una poderosa analista de los acontecimientos políticos y económicos, y en una perspicaz pensadora feminista. En el proceso, también aprende a percibir su propia opresión como mujer pobre y salvadoreña, y comienza a ver el mundo a través de los ojos de su propio sexo" (1). Para insistir en las dimensiones feministas de la experiencia de su sujeto, Stephen llega a enfatizar escenas de violación, de abandono y de abusos sexuales y domésticos, como episodios clave de esta narración. Aun más, Stephen aprovecha el formato testimonial, popular en los Estados Unidos y en el extranjero, para difundir un mensaje en favor de la organización de prostitutas, amas de casa y madres solteras, y de la formación de un programa de derechos humanos que coincida con la plataforma feminista.

El aparato narrativo transforma las ideas de Tula en una historia de iluminación de la conciencia chapada a lo norteamericano. A diferencia de Rigoberta Menchú, que guarda secretos nacionales y nunca abandona el compromiso con su partido político, Tula se salta todo límite de fe y narrativa para adoptar una perspectiva norteamericana que contrarresta su papel de "víctima". Stephen explica al respecto: "Lo que hace a la historia de María distinta de otros testimonios de mujeres es que ella se identifica directamente tanto con el feminismo como con la marginación y opresión de las mujeres en la sociedad salvadoreña y en los movimientos populares de la izquierda" (126). Entre otras cosas, nos enteramos de que María Teresa Tula, en un viaje a Europa en nombre de su organización, ha llegado a aceptar el lesbianismo de otras mujeres; ella justifica esta aceptación como parte de un reconocimiento general de las dimensiones totales de las vidas de las mujeres. La editora pasa a insistir en que lo testimonial debe revelar la experiencia femenina como una toma de conciencia y proporcionar a sus lectoras con "un importante modelo de análisis feminista" (227). Entretanto, emerge una construcción narrativa que muestra los poderes de rescate y conversión ejercidos sobre el sujeto latinoamericano.

Un esfuerzo más notable de mediación cultural es el ofrecido por Ruth Behar en su libro Translated Woman (1993). Rayando en la ficción y la autobiografia, el proyecto de Behar responde a las críticas presentadas contra aquellas investigadoras que pretenden realizar una transcripción de una "vida" latinoamericana. Así, Behar da cuenta de las dificultades de transcribir las experiencias de sus sujetos y de sus propios esfuerzos como escritora situada entre dos mundos. En este sentido, la historia de Esperanza se convierte en un pretexto para contar la historia de Behar. También presenta una serie de problemas relacionados con la construcción de narrativas de mujeres.

Behar está ampliamente formada en los lenguajes de la crítica y está excepcionalmente familiarizada con el debate acerca del "etnógrafo redentor". Su proyecto consiste, pues, en unir la antropóloga con su sujeto - las dos son descritas a lo largo de la obra como "comadres" - como colegas en la tarea común de registrar el "testimonio" y de participar en el arte de la escritura. Aquí Behar proclama la diferencia existente entre ella y los etnógrafos más convencionales. Su identidad va cambiando; sus viajes entre el norte y el sur, y su capacidad bilingüe, le permiten oscilar entre varias identidades postmodernas; asimismo, su condición de latina en el medio universitario estadounidense, con una reconocida carrera dentro de los estudios literarios, le permite a Behar mezclar la narrativa personal y privada con 
la ficción, dejando así de lado la objetividad que supuestamente se espera de un documento antropológico. Esto se va haciendo evidente a medida que Behar conecta las tendencias hechiceras de su sujeto con la ficción del "realismo mágico", acercando el texto a esa narrativa de fantasía por la cual la literatura latinoamericana es mayormente conocida en el exterior. Además, las estructuras de ficción son mantenidas a lo largo de todo el libro, solamente interrumpidas cuando la autora inserta sus reflexiones autobiográficas. De este modo, al contar sus historias, Esperanzay su narradora quedan unidas en un pacto por el cual se enfatiza el proceso creativo. Lo que queda es un "retrato de la artista" en el cual la protagonista controla la experiencia de nombrar con el objeto de enfocarla hacia un proyecto optimista de cara a las relaciones Norte/Sur.

En Death Without Weeping (1992), Nancy Sheper Hughes analiza los importantes problemas de relativismo cultural surgidos recientemente dentro de la crítica antropológica. Su estudio trata sobre los conceptos éticos que "fantasean al otro" ("othering the other") y sobre los peligros que derivan de éstos, a la vez que cuestiona si la moralidad puede dejarse fuera de los estudios culturales. Su estilo narrativo está dedicado a explorar estas cuestiones a la vez que elabora una defensa de la antropología como campo de acción, una subversión de las relaciones existentes entre el poder y las jerarquías del saber. Así, en su condición de mediadora cultural, Hughes organiza una narrativa sobre el compromiso personal con su objeto de estudio y cuenta su propia experiencia como elemento central del "relato". De esta manera, el relato antropológico se aproxima a la ficción, al estar cargado de drama narrativo y de fuertes tensiones con desenlace final. Incluso las gráficas descripciones de muertes y de destrucción corporal proporcionan elementos de suspenso y, de un modo perverso, detalles morbosos. Aquí lo abyecto adquiere su propia estética.

Hughes nos advierte repetidamente de los peligros de la excesiva producción de diferencias (315) en tanto que ésta elimina cualquier área de discusión común entre los sujetos latinoamericanos y los académicos norteamericanos. A pesar de esta observación, me pregunto si esta manifestación de diferencias no es precisamente el rasgo principal que hace a Latinoamérica atractiva a los ojos estadounidenses. El modelo de estudio construye un excedente de excentricidades que invita a la intervención y al análisis del crítico norteamericano, que a su vez desarrolla una narrativa acerca de la comunidad y la restitución del orden. En cualquier caso, la narrativa de Hughes se sitúa de manera precaria entre estos extremos, ya que su relato toma la forma de un melodrama basado en un caso de muertes infantiles mientras que ésta también alaba las dotes de supervivencia de la comunidad brasileña que está estudiando. Es precisamente este ansia de comunidad, a menudo una búsqueda de un mundo perdido que podría restaurar un antiguo modo de vida, lo que subyace en el centro de este tipo ficción estadounidense que a veces se contagia a los escritores del Sur. La nostalgia y el horror que rodean a la familiay a la comunidad, encuentran, por supuesto, su paralelo en textos que entran claramente dentro del género de ficción; sólo hay que pensar en Paula, de Isabel Allende, o Como agua para chocolate, de Laura Esquivel, obras que insisten en el papel central de la familia y el clan. A juzgar por su condición de best-séllers, sobre todo en los Estados Unidos, parecería que nuestra sed de ficciones familiares latinoamericanas es ilimitada.

A través de estas lecturas, estamos presenciando el drama de un nuevo tipo de representación política en el medio narrativo. Estas obras vuelven a prestarle atención a la familia y sitúan al científico social como "productor inspirado". A su vez, estos libros 
envuelven en romanticismo a la figura del marginado que se rebela contra la hegemonía del estado actual.

Estas narrativas antropológicas ocupan un lugar significativo en la economía cultural de las relaciones Norte/Sur, confirmando una percepción determinada de las mujeres latinoamericanas; trazan tipos de identidad femenina e incluso prescriben modelos de actuación, contenidos en una manera de narrar que sin duda se basa en lo ficcional. Bajo el disfraz de realismo mágico, de historias de "retrato del artista", o de narrativas de derrota y triunfo, estas ficciones representan diversos dramas de víctimas oprimidas por la sociedad. Y a pesar de sus aspiraciones a lograr identidades móviles, sus objetos de estudio se convierten en fuentes de "autenticidad" para Latinoamérica. De este modo, las historias se quedan a caballo entre un carnaval postmoderno de identidades variables y una nostalgia por las tradiciones familiares y la cohesión comunitaria de antaño; todas coinciden en la reflexión autocrítica por parte de la antropóloga sobre la subjetividad de la gringa que valora los elementos del arte narrativo más que el frío empirismo de los datos.

Si llamo la atención sobre estos proyectos, es para revelar las maneras en que los problemas del género en Latinoamérica son incluidos dentro de los discursos críticos donde invocan una colaboración entre sujeto e investigador y terminan con algo parecido a una ficción literaria. El "experto", tan aclamado por el movimiento neo-conservador, redefine ahora la autoridad en relación al arte de contar y escribir, y a la celebración de los logros de las mujeres unidas por el encuentro Norte/Sur.

A modo de continuación con las meditaciones de las antropólogas ya mencionadas, Amy Kaminsky, perteneciente al campo de la crítica literaria, escribe que la deconstrucción de la experiencia femenina está diseñada para "desafiar la posición de inferioridad de la mujer respecto al hombre" (18). Este tipo de crítica, explica Kaminsky, debe proponerse "como uno de sus objetivos, la transformación de la práctica represiva de la cultura" (xiv). Como sus colegas citadas más arriba, Kaminsky también está buscando patrones alternativos de identidad femenina, y decide decantarse por la concepción postmoderna de un yo femenino móvil. En el proceso, surge una curiosa paradoja: mientras que la antropóloga tiende hacia una construcción ficcional, la especialista en literatura busca una realidad objetiva. Así, esta última eleva las tipologías feministas a fundamentos del estudio literario: la exiliada, la lesbiana y las protagonistas del "testimonio" forman la base del análisis literario.

Debra Castillo ofrece una interesante especulación al respecto, cuando comenta con perspicacia que desde la perspectiva de la metrópolis, "las mujeres latinoamericanas no escriben. De esta afirmación derivan otros corolarios, otros tópicos de la historia literaria latinoamericana convencional. Las mujeres latinoamericanas desde luego no escriben prosa. Lo poco que hacen - mayormente poesía - se merece el olvido" (26). Para corregir esta visión, Castillo se propone demostrar las maneras en que las escritoras cuestionan las normas de autenticidad y funcionalidad de los textos en su calidad de materias tanto teórica como práctica (33). Castillo quiere evitar juicios absolutos y trascender las categorías de análisis occidentales para encontrar otros criterios teóricos evaluativos. Sin embargo, en un intento que se parece en gran medida al impulso antropológico por definir las jerarquías de los sexos, ésta decide nombrar a las mujeres latinoamericanas en su condición de sujetos marginales: amas de casa, indias y santas, prostitutas y analfabetas (293-294) son colocadas en una "serie de situaciones temporales" (7) sin quedar limitadas por una teoría particular. Su estrategia se 
parece a la receta de un estofado: "Una pizca de esto, y una pizca de lo otro" (36). Basándose en las propuestas teóricas de Derrida, lo indeciso ("undecidability") es lo que le da sabor al guiso narrativo de esta obra; de esta manera, los ingredientes que se van añadiendo a la olla hirviendo se asemeja a un tipo de lectura en la cual no se pueden distinguir las partes del todo. Irónicamente, los relatos femeninos se inscriben, una vez más, en una ficción doméstica.

La autopista panamericana construida por las mediadoras culturales está repleta de amas de casa y prostitutas, de víctimas o de tenaces supervivientes. ¿Existe alguna otra manera de imaginar este panorama sin poblarlo de sujetos marginales? ¿Cómo vamos a tratar las relaciones Norte/Sur desde nuestro papel de mediadoras culturales? Si he señalado los ejemplos anteriores, no ha sido a modo de condena, sino para reflexionar acerca de nuestras visiones como académicas estadounidenses comprometidas con Latinoamérica. Ciertamente, nuestras posiciones al respecto no han pasado desapercibidas. La poeta argentina, Susana Thénon, ha escrito un cáustico poema aludiendo a los intereses de las críticas norteamericanas supuestamente dedicadas al feminismo. Su texto se burla del proyecto de una crítica literaria que pretende compilar una antología de escritoras latinoamericanas. El poema concluye con los siguientes versos puestos en boca de la norteamericana:

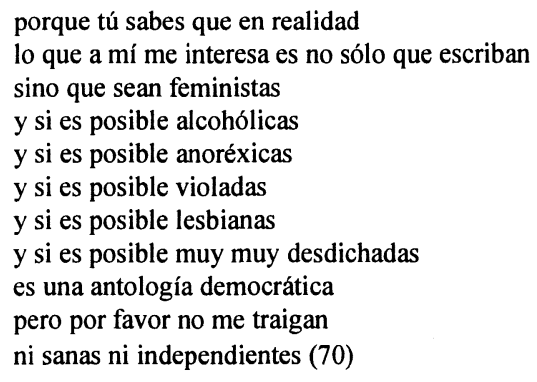

La irónica meditación de Thénon nos lleva a examinar la recepción de las ideas feministas norteamericanas en el Sur. Con una dosis menor de ironía, y de manera más efectiva, la escritora argentina María Negroni plantea este mismo problema en su libro de ensayos Ciudad gótica (1994). Ésta observa cómo se espera de la cultura latinoamericana que cumpla una promesa de diferencia, lo cual conduce a un gueto de textos y comportamientos excéntricos:

En el plano literario, la "guetificación" lleva a confusiones alarmantes. Los escritores "latinos" están condenados a un deber ser implícito y férreo. Algo así como un arquetipo platónico vertido en el molde de un mandato explícitamente político o exótico o folklórico. Aquí se acaba la lista .... ¿Quiénes son los responsables de este desaliento? ¿Los que producen? ¿Los que trabajan de agentes literarios? ¿Los que consumen? ¿Los que organizan? ¿Difunden? .... Me temo que, mientras persistan los síntomas que he descrito, pocas expectativas puedan cifrarse allí. Al menos, hasta que América Latina gane lo único que no se le concede: el derecho a participar, de igual a igual, en la discusión estética (29$32)$.

Con el objeto de moverme en esta dirección, me gustaría examinar ahora los proyectos de aquellas mujeres de Argentina y Chile que se ocupan del intercambio de ideas Norte/Sur 
dentro del medio de la revista cultural. En este medio, ellas abren nuevas vías de discusión para la cuestión del género y la práctica social.

\section{Medi(T)ACIONES SUdAmERICANAS}

Siguiendo una tradición que aún permanece fresca en el recuerdo con el ejemplo de Margaret Randall, que fue a Méjico en los sesenta para fundar la revista El corno emplumado y así abrir un diálogo entre poetas a ambos lados de la frontera, los proyectos intelectuales de Lea Fletcher y Nelly Richard, extranjeras que en la actualidad residen en Argentina y Chile, mantienen un diálogo Norte/Sur a través de las publicaciones culturales. En mi opinión, Feminaria y Revista de Crítica Cultural (dirigidas, respectivamente, por Fletcher y Richard) se encuentran entre las más importantes publicaciones latinoamericanas orientadas hacia el intercambio Norte/Sur con el fin de tratar cuestiones de política local, de estética o de género. Igualmente importante es el hecho de que vuelven del revés el tipo de narrativa heroica de mujeres que es a veces sustentado por el Norte.

Feminaria (1988 -) es una labor destinada a integrar la teoría feminista del Norte con la producción intelectual del Cono Sur. Su directora, Lea Fletcher, norteamericana de nacimiento y residente en Argentina, ha contemplado dos ciclos de reflexión feminista con el objeto de concentrarse en la cultura y el lenguaje. En su primera fase, Feminaria anunció un programa de estudio de la influencia de los valores patriarcales sobre las mujeres argentinas y de exposición del sexismo en el lenguaje (Fletcher 1988:1). Este proyecto estaba documentado con artículos de feministas europeas y estadounidenses, yuxtapuestos a escritos de mujeres argentinas de los campos de la literatura y las ciencias sociales.

Como era de esperar, la presentación de este material siempre ha estado fundada en una teoría de la conversación entre mujeres y una fe manifiesta en las posibilidades que este diálogo podría ofrecer. Es precisamente esta teoría de la conversación, desarrollada durante los ocho años de historia de Feminaria, la que le ha dado forma al necesario discurso sobre identidad, estética y acción. Rechazando el modelo de un "gueto" de mujeres, Feminaria ha optado por la construcción de una comunidad de interlocutoras que guíen las prácticas feministas dentro de la cultura argentina contemporánea (i.e., Monzón 1992:8 5).

Desde el primer número, Fletcher publicó piezas de la feminista italiana Rossana Rossanda y de mujeres argentinas en el extranjero sobre la base de la amistad femenina y de la urgencia discursiva que esta relación produce. Aparecieron artículos sobre los puntos de reuniones feministas, incluyendo el primer (y todavía muy celebrado) encuentro de feministas argentinas y chilenas ocurrido en Santiago bajo la dictadura, y los posteriores congresos feministas celebrados en otros lugares de Latinoamérica junto con la publicación de actas seleccionadas, además de comentarios sobre librerías de mujer en París y Buenos Aires, y sobre los programas de estudios de la mujer en las universidades argentinas; en todo momento, Fletcher siguió proporcionando bibliografias de los más recientes trabajos sobre temas feministas argentinos. Estos datos componen un registro de las prácticas intelectuales feministas en Argentina, ofreciendo una puesta al día en las teorías de acción social y una revisión panorámica de la producción cultural. Entre ellos destacan los informes sobre la participación de la mujer en la sociedad de la era neoliberal.

Reflexionando sobre el clima político actual provocado por la economía de mercado, la crítica cultural Leonor Calvera observó: "La discontinuidad intrínseca se ve alimentada por 
una malsana discontinuidad exterior, provocada. Es un hecho que, abierta o encubiertamente, el manejo de la opinión pública tiende a romper la continuidad de la experiencia feminista. Se habla de superación o de fracaso. Lo que importa es separar los distintos momentos de las luchas reivindicatorias o transformadoras, aislarlas para quitarles coherencia. De esta manera cada mujer se siente fuera de un destino común .... La quiebra en la unión de los distintos tiempos y lugares, con la consiguiente abolición de la facultad evocadora, ha sido una de las principales características del terrorismo de los grupos de dominación, especialmente del Estado" (1992:8 6). Para combatir este aislamiento, Feminaria buscó una continuidad entre los movimientos de la mujer del periodo contemporáneo con los de épocas anteriores. Así, Fletcher nos proporcionó las raíces históricas de las luchas de las mujeres argentinas: las notas sobre Juana Manuela Gorriti y Eduarda Mansilla de García, y sobre la generación argentina de los 1880 nos presentan el antecedente decimonónico de los feminismos contemporáneos; los análisis de los primeros congresos feministas panamericanos o de las reuniones literarias convocadas por mujeres en los años veinte traen la investigación ya al siglo actual; además, una casa editorial que trabaja conjuntamente con la revista se dedica a recobrar archivos.

Simultáneamente, las colaboradoras argentinas de Feminaria se cuestionaron las posibilidades del feminismo en un país dependiente cuyo patrón de ideas siempre ha derivado de los Estados Unidos y Europa. Las colaboradoras de Fletcher criticaron así las categorías de conocimiento distribuidas entre los círculos angloamericanos. Especialmente sometida a examen es la lógica binaria usada por la teoría estadounidense para marcar la diferencia sexual: los modelos de agresión/pasividad (Brownmiller, Dworkin); naturaleza/cultura (Ortner, Griffin); o el concepto de diferencia como forma de conciencia que promueve la superioridad de la mujer (Chodorow, Gilligan). Las escritoras y filósofas asociadas con Feminaria orientaron esta reflexión crítica a la consideración de la política de identidad resultante de la lógica binaria.

Al respecto de la imposición de premisas teóricas angloamericanas, la poeta y crítica argentina Diana Bellessi comentó que las mujeres del Cono Sur siempre están trabajando bajo la presión de un "imaginario hipotecado". El adoptar las estrategias de los feminismos europeo y norteamericano en una cultura doblemente colonizada pone de antemano a las mujeres argentinas en una situación precaria y amenaza sus certezas epistemológicas:

Cuestionar una cultura central intrínsecamente colonizada por Europa, desde la instrumentación de un pensamiento resistente también fundado en Europa, es una cosa. Incluir la precariedad bárbara de un feminismo teórico oriundo del norte, aún poco leído, apenas traducido y ya cuestionado, exige una rápida producción local por parte de mujeres involucradas personalmente desde el espacio doméstico de sus vidas y es otro fenómeno harto más difícil. Significa enfrentarse a una doble hegemonía cultural desde una diferencia de la que apenas empezamos a ser conscientes. Cuando no se tiene siquiera el poderoso arsenal de un pensamiento mítico fundado en las culturas indias, para oponerse al discurso central colonizador, lo es más aún. Hay que trabajar con un imaginario hipotecado. Poner el cuerpo allí, encierra el peligro de pasar a ser la Tonta. Significa desplazar el impuesto interés por el prestigio, hacia el interés por el erotismo. Despreciar el aplauso de los reyezuelos en el palacio, por la algarabia amorosa de otras mujeres. En un ambiente donde no se arriesga demasiado desde lo personal, abrirse el corpiño y demandar ser miradas y mirarse (1990:6 10). 
Ampliando en cierto modo el argumento de Bellessi sobre la necesidad de asumir riesgos teóricos a nivel local, la filósofa Diana Maffia toma las experiencias políticas argentinas actuales como base para el pensamiento crítico. Este es el caso de su narración de la historia de Marisela, una transexual cuyos hijos fueron forzados a abandonar su casa bajo la acusación de que ella no era apta como madre (1994:12). Esta anécdota, publicada en los diarios de Buenos Aires y largamente comentada en 1993, le inspira a Maffia a considerar en primer lugar las categorías "naturales" de identidad sexual y, sobre todo, en segundo lugar, los cambios en las relaciones entre la sexualidad y el poder político en Argentina. Igualmente, la prohibición del aborto - un asunto polémico en Argentina - inspiró la publicación de un número de Feminaria dedicado a los límites de la filosofia liberal desde la perspectiva del Cono Sur, mientras que números posteriores afrontaron directamente la crisis de la democratización en relación a la situación de las mujeres. Como protagonistas de la sociedad de mercado, las mujeres resultan ser las figuras más gravemente afectadas por el régimen neoliberal, responsables tanto de la supervivencia de la familia como del mantenimiento económico del hogar. Aun más, a pesar de la opinión conservadora sobre la pérdida general de valores y el detrimento que supone el predominio de la economía de mercado para la sociedad civil, aparecen ahora múltiples posibilidades para la organización de mujeres. Se producen así nuevas expresiones de acción social así como un desafío de las formas de autoridad tradicionales (Maglie 1990: 5 29-31). ${ }^{7}$ La proliferación de nuevas identidades es acogida como una respuesta positiva a la crisis del régimen neoliberal. En esta revista, las fuentes de investigación son claramente heterogéneas, ya que provienen tanto de intelectuales locales como de expertas en política de los Estados Unidos e Italia. En todo momento, sin embargo, las críticas argentinas siguen negociando las condiciones específicas de las mujeres de su país.

Esta crítica se ve de manera más clara en relación con la cuestión estética. En un inteligente ensayo, la escritora de creación Tununa Mercado examinó las voces de denuncia que iban apareciendo en los movimientos feministas contemporáneos con el objeto de evaluar el impacto de ese discurso sobre las actividades de mujeres escritoras. Queriendo enfatizar una posición que no queda lejos de mis propios sentimientos al respecto, Mercado escribió:

Esa literatura de denuncia y de agitación se acostó en un molde: se pensó que para llegar a las trabajadoras, a las campesinas o a las secretarias, que son a quienes quieren llegar al menos las feministas socialistas, había que formular un mensaje directo e inconfundible. La intención nos obligó a muchas a hacer recortes y, a la larga, tuvo un efecto represivo. En el ámbito de las ciencias sociales llamado de "estudios de la mujer", los textos siguieron modelos académicos tradicionales, se instalaron en un cuerpo ordenado, taxonómico, clasificatorio del papel de la mujer y de su condición en la sociedad. Había que hacer una ciencia de la mujer, constituir una teoría, pero no se puso en crisis el lenguaje, no se creyó necesario hacerlo entrar en crisis: en toda la vasta literatura sociológica hay muy pocos textos que muestran el desagarramiento y la perplejidad de la escritura, como si todavía no se pudiera salir de la descripción y de la interpretación hacia una epistemología que pueda dar cuenta de la complejidad de la materia sobre la que se discurre.

\footnotetext{
7 Acerca del papel de las mujeres en la economía neoliberal, ver los dossiers especiales de artículos: "Mujer y crisis", 1990:5 29-35, y "El feminismo en estos tiempos neoliberales", 1992:8 3-14.
} 
... El tema, los temas — la llamada "problemática" femenina-y me atrevo a decirlo, poco a poco fue subyugando esos textos y condenando a una nueva opresión, la del referente "real", que exige sumisión y se adueña del gesto narrativo haciéndolo ilustrar con verdad, verismo o verosimilitud lo que no le sucede a sus criaturas de ficción, quedando así el relato y la escritura demasiado pegados a la dictadura de la representación, mimetizándose el texto con la literalidad del mensaje. Esta narrativa se miró en la luna del espejo, no atravesó el espejo (1989: 3 22).

Aunque Feminaria ha publicado artículos estadounidenses de inspiración postmoderna (Flax, De Lauretis, Benhabib), es quizás a través del énfasis en la literatura donde el enfrentamiento de las distintas culturas del Norte y del Sur es percibido con más intensidad. Aquí, la "crisis del lenguaje" señalada por Tununa Mercado se convierte en objeto de un profundo análisis. Comenzando con el número 7 de la revista (1991), Feminaria inauguró una sección titulada "Feminaria Literaria" para concentrarse en un enfoque histórico comparativo de la producción cultural feminista. Los nombres de Elizabeth Bishop, Adrienne Rich, y Nicole Brossard, se unieron a los de escritoras y críticas contemporáneas de Argentina y de otros países latinoamericanos. De este modo, Fletcher equilibró la demanda de la crisis política contemporánea, que enfatizaba los derechos de la mujer y su participación en las reformas estatales, con los estudios del arte de la escritura y con la intersección de culturas Norte/Sur. En resumen, el proyecto sigue resistiéndose a las categorizaciones esencialistas de la experiencia local.

En Chile, Nelly Richard, otra extranjera en Latinoamérica (es francesa pero lleva más de veinte años viviendo en Chile), nos presenta una interpretación radical de las relaciones Norte/ Sur en su Revista de Crítica Cultural (1990-). Aunque su propósito no es el de concentrarse en temas feministas solamente, Richard plantea una crítica de los debates postmodernos y una búsqueda de la identidad latinoamericana tal y como es vista desde la perspectiva analítica del género. Así, ésta lleva a cabo un examen local del feminismo latinoamericano, defendiendo el valor de la micropolítica y ensalzando la influencia de la literatura y el arte visual.

En general, Richard trata la teorización global con ojo crítico; desconfia de los impulsos universalistas, pero también reconoce las ventajas de los conceptos metropolitanos a la hora de afrontar problemas de la cultura latinoamericana. Consecuentemente, Richard rechaza un uso restringido del término "postmoderno" ya que éste podría interferir en la acción social propiamente dicha, ${ }^{8} \mathrm{e}$ insiste constantemente en la autonomía heterogénea de la cultura local. Sin embargo, Latinoamérica debería aprovechar la línea argumental postmoderna para participar en el circuito de discusión global:

Es posible argumentar a favor de un interés latinoamericano en el debate postmoderno diciendo que somos parte interdependiente de la red de planetarización de las influencias que pone en contacto telecomunicativo el aquí-ahora de todos los sujetos receptores diseminados en el centro y en la periferia de la información cultural. Esta mundialización de la cultura, nos obligaría de por sí a tomar posición para no perder "conciencia situacional"..... Mucho de lo que disgrega el rostro postmoderno (de la rotura del nexo societal al vaciamento de los

\footnotetext{
${ }^{8}$ Sobre la recepción de la teoría metropolitana, ver en particular el número de $R C C$ dedicado a la visita de Baudrillard a Chile (1993:7).
} 
referentes-guías de movilización y lucha) se refleja entre nosotros, aunque oscurecido por el dramatismo de una convulsión histórica (las dictaduras) que estremece la tesis de cualquier relajado "fin de la historia" defendido hoy por los apocalípticos integrados. .... Todas estas razones derivadas de la crisis de totalidad-centralidad argumentarían a favor de la revalorización cultural de la periferia hasta postularla máxima protagonista del nuevo relato posmoderno de lo descentrado (1991:3 15-19).

De la misma manera que el "boom" literario hizo a Latinoamérica destacarse en el mapa mundial, el postmodernismo latinoamericano (tan antiguo como el propio siglo, dirían algunos) ha de ser visto no sólo en conjunción con las corrientes europeas y estadounidenses, pero también como la fuerza que permite a los latinoamericanos reflexionar sobre su posición periférica dentro del proceso de modernización, sobre las anacronías entre la cultura y el desarrollo económico, y sobre el pastiche formado por la memoria y el olvido históricos.

El postmodernismo en Latinoamérica está determinado por su propia heterogeneidad, por los encuentros entre tradición y modernidad, y su insegura combinación. Es precisamente esta híbrida mezcla, este collage inestable, lo que crea una alternativa a los acostumbrados proyectos de modernidad del así llamado mundo desarrollado; aquí, la inconclusa circulación de materiales heterogéneos abre la posibilidad de una nueva voz política que sepa responder a los Estados Unidos y a Europa en sus propios términos.

A continuación, Richard intenta derivar dela crisis generalizada de discursos totalizadores, una demostración de las maneras en que los diferentes niveles de desarrollo en Chile, Argentina, y Perú, desmantelan los ideales de historia y progreso para abrir el paso a la micropolítica. Su objetivo es el de revelar lo que ella describe como "la fisonomía del "nosotros mismos"' (1991:3 15). Por tanto, Richard se niega a abandonar sus vínculos con cualquier proyecto local y encuentra así en la cultura de la heterogeneidad y el mestizaje una productiva base lógica para el postmodernismo "periférico". El siguiente paso consiste en trasladar esta discusión al terreno del género.

Richard se declara a favor de una alteridad latinoamericana peculiar y en contra de nociones hegemónicas. De este modo, si el pastiche, la cita y los simulacros abundan en los proyectos postmodernos internacionales, Richard ve su utilidad dentro del contexto local como respuesta a la cultura metropolitana. La parodia, por ejemplo, es una manera de subvertir la autoridad de la cita; no constituye una imitación servil o un fenómeno de "déjàvu".

Los trabajos de traducción, que inundan Latinoamérica, son vistos como proyectos contestatarios. De la misma manera que Sarmiento distorsionó las culturas europeas al traducir del francés al español, restándole fuerza a las tradiciones de prestigio internacional de aquel entonces, la práctica del pastiche y la cita en la Latinoamérica actual no deben ser tomadas como una falta de originalidad, sino como una resistencia consciente contra las formas de expresión metropolitanas. ${ }^{9}$ Son maneras de proclamar la singularidad de Latinoamérica, reivindicando su alteridad y oponiéndose a la dominación.

Todo esto encaja perfectamente con el proyecto más general de Richard de rescatar los micropoderes de la política cultural, como manera de insistir en el influyente papel del género

\footnotetext{
${ }^{9}$ Sobre la cuestión de la traducción y las ventajas estratégicas de la cita distorsionada, ver la obra de Ricardo Piglia (1994).
} 
sexual a la hora de establecer la autonomía latinoamericana. Las colaboraciones sobre feminismo e identidad social de las chilenas Diamela Eltit, Olga Grau, Mabel Piccini y Raquel Olea, o las de Néstor Perlongher, Félix Guattari y Jacques Derrida sobre cuestiones de sexualidad y Estado, les recuerdan a los lectores de Revista de Crítica Cultural la innegable importancia de la identidad sexual dentro del proyecto postmoderno; los efectos desestabilizadores de dicha identidad son también una manera de desarrollar modelos de Estado alternativos. La feminización aparece a menudo en la Revista de Crítica Cultural como un principio fundamental de alianza política en Latinoamérica. En este sentido, el poeta argentino Néstor Perlongher comenta, refiriéndose a Brasil, que las minorías sexuales y raciales agitan el cuerpo social en un intento de volver a tomar las instituciones, 0 , en el análisis final, de destruirlas. Pero Perlongher se apresura a observar que las minorías culturales no están únicamente preocupadas por su identidad, sino también por la posibilidad de convertirse en componentes de alianzas con otras minorías. Al respecto de las minúsculas entidades compartidas por los distintos grupos (aquí se nota la influencia de Deleuze y Guattari), el autor propone que la femenina es la que ejerce mayor oposición contra el Estado. Son sobre todo los contactos entre grupos minoritarios marcados por la identidad sexual los que tienen la mejor oportunidad de alterar la subjetividad latinoamericana en general; en última instancia, estos grupos ofrecen la posibilidad de una mutación del orden global basada en categorías sexuales (1991:4).

Richard rechaza cualquier categoría absoluta del sujeto latinoamericano. A cambio, defiende una libre proliferación de discursos asociados con las minorías sociales, discursos que son capaces de abrirse a los márgenes sin la necesidad de recurrir a tópicos de persecución o triunfo. El proyecto de Richard devuelve una y otra vez a los lectores a las complejas realidades de Latinoamérica. Un breve ensayo de Diamela Eltit (1991:4) reitera este aspecto cuando ésta describe la función de la vestimenta en cuestiones de ciudadanía, heroísmo y autoridad. Eltit toma el ejemplo de un héroe de la revolución mejicana, una mujer vestida de hombre. Ésta ocultó su identidad para eludir el control del Estado y jugar con los códigos que definen el heroísmo de cara al público. Para Eltit, el travestismo es un espectacular ejemplo del cruce de categorías de ciudadanía, de cómo la identidad sexual y el heroísmo quedan unidos al servicio de los ideales patrióticos. Anticipando de alguna manera el debate acerca del reciente retrato realizado por Juan Dávila de un Simón Bolívar travestido, que inspiró la ira de los oficiales de estado latinoamericanos (un tema central en el número 9 de la publicación de Richard), Diamela Eltit desenmascara la carga masculina atribuida a las visiones heroicas y denuncia como igualmente sospechoso cualquier otro intento de fijar una identidad bajo la ley del Estado. Finalmente, propone que el proyecto social de las minorías sociales es una manera de vencer las formas estéticas comerciales promovidas en el mercado global.

Dado el énfasis en la hibridación, no resulta sorprendente que gran parte del material de Revista de Crítica Cultural esté dedicado a los temas de las identidades móviles, tanto nacionales como sexuales, en Latinoamérica: el mestizaje, el reciclaje de las vestimenta y la identidad, y los simulacros que constituyen la vida cultural moderna, reciben la atención de los colaboradores de la revista. Aun más importante es el hecho de que estos fenómenos no son tomados como tropos postmodernos; por el contrario, estas imágenes son utilizadas para refutar la autoridad del discurso metropolitano. En las identidades travestidas radica, según estos autores, la oportunidad de perder la máscara. 
Pero Richard también está interesada en los efectos de la máscara y la importancia de las identidades sexuales no fijas para la evolución de la cultura democrática. En su sagacidad Richard considera las críticas del Estado por parte de estas minorías sexuales como un desafío a las prácticas hegemónicas pero también como una manera de apoyar las tendencias aparentemente liberales de un gobierno democrático. Esta posición dual le permite a lo "femenino" poner en duda el centro de autoridad masculino, pero es a su vez usada por el estado democrático para demostrar la participación popular. En este sentido, Richard busca maneras de acomodar la práctica feminista dentro de las realidades del Chile post-dictatorial, o de situar dentro de debates metropolitanos más generales el proyecto feminista de apertura de una discusión sobre la identidad latinoamericana. Su meta es, pues, el encontrar un lugar acogedor para los gestos en apariencia radicales anunciados por la teoría feminista, y el aprovechar la teoría metropolitana para fomentar los objetivos feministas: "el feminismo latinoamericano debe también preocuparse de saber cuáles son las ranuras e intersticios de la teoría metropolitana que podrán ser aprovechados para torcero desviar a su favor el paradigma del Otro", escribió Richard en su reciente libro Masculino/Femenino (1993: 80). Esta cita puede servir de resumen de los programas feministas presentados en su revista, es decir, de cómo se aprovecha al máximo el caldo de la teoría postmoderna para así poder alimentar a todos los comensales del banquete Norte/Sur. Entretanto, se crea un lugar para las mujeres latinoamericanas en los debates metropolitanos, donde tendrían la oportunidad de redefinir su condición de "otras".

A la vez que el corpus de crítica cultural recogido por Fletcher y Richard se ocupa de la política de la teoría internacional y de la acción democrática local, también va produciendo nuevas y desconocidas subjetividades que se oponen al tópico de la víctima. En este sentido, los deseos contra-utópicos manifestados en las páginas de Revista de Crítica Cultural y Feminaria consiguen despejar cualquier ilusión de un discurso uniforme sobre la mujer. Lo que es más, se insiste en el potencial del feminismo latinoamericano para articular una crisis de representación tanto en los paradigmas metropolitanos de la teoría postmoderna como en los proyectos neoliberales de democratización en Latinoamérica.

\section{Contestar a Occidente: Estética y Representación}

Tanto Feminaria como Revista de Crítica Cultural trascienden las fuentes teóricas procedientes del Norte al llamar la atención sobre una estética marcada por el género sexual, y al buscar los elementos específicos del arte que se resisten a los efectos de la globalización. Es precisamente en el territorio del placer estético, aún sin codificar ni siquiera por los teóricos más exhaustivos, donde el significado fluye libremente, superando al lenguaje de la represión. Es la estética, por tanto, la que ofrece una manera de revocar las demandas del mercado global para reconsiderar cuestiones de representación, tanto en política como en arte.

De este modo, la obra de arte adquiere una fuerza que se podría describir como una "capacidad negativa", un abandono de la circulación en serie que insiste en expresiones alternativas, en "lecturas" alternativas del encuentro Norte/Sur y del estado neoliberal controlado por el mercado. Desde dentro del terreno artístico, se pueden compensar los efectos de la segregación de la experiencia y del colapso de la tradición y la lógica. Se nos permite redescubrir en el arte un lazo común, y buscar en él un tipo de afinidad ajena al mercado; 
también nos hace posible el redefinir las relaciones Norte/Sur independientemente de las ventas y el lucro. Como espero haber demostrado en la primera parte de este ensayo, las investigadoras norteamericanas, sin duda, han captado el potencial de la ficción para generar nuevos modelos de alianza, pero es en el campo de la literatura latinoamericana donde se percibe un esfuerzo más enérgico, destinado a intervenir en el reparto de identidades fijas establecidas por los patrones angloamericanos.

En este sentido, no nos sorprende que gran parte de la literatura argentina y chilena dedicada a proyectos feministas, recurra a textos anteriores de la tradición angloamericana, en parte como homenaje a las vanguardias artísticas, pero también como medida contra las visiones antiestéticas del actual circuito transnacional. Curiosamente, los defensores del modelo neoliberal también proponen ir hacia atrás en el tiempo, de vuelta a una era más estable y convencional de "verdades" inmovibles. Esta propuesta se basa en la nostalgia, pero la mirada estética al pasado cumple una misión distinta, que en cierto modo intenta anular la premisa neoliberal de una verdad absoluta así como abrir un ruta alternativa que una las culturas del Norte y el Sur. Esto no constituye un mero reciclaje de imágenes sino otra manera de ampliar el diálogo, de tomar parte en la discusión general sin abandonar los principios de identidad artística. En esta línea, el año pasado Graciela Safranchik, una de las escritoras argentinas actuales de más talento, publicó Kadish, una novela cuyo título evoca el poema de Allen Ginsberg, aunque su lectura más precisa sería como tributo a la novela de Vita Sackville West, All Passion Spent. De manera similar, la poeta y editora argentina Mirta Rosenberg ha asumido la responsabilidad de traducir al español los escritos de Mina Loy y H. D. Su casa editorial, "Bajo la luna nueva", ya ha publicado una novela corta de Joyce y una traducción de Katherine Mansfield. Esto constituye un intento de volver en el tiempo para recuperar una versión más temprana de los intercambios angloamericanos, cuando la modernidad era menos hostil, menos ofensiva al temperamento estético. ${ }^{10}$ También representa un momento en el que la vanguardia tiene posibilidades de triunfar en el terreno de las ideas. ${ }^{11}$ Esta empresa se puede comparar con los esfuerzos paralelos de otras escritoras argentinas por revisar los efectos del museo, o institución metropolitana que restaura el significado de la cultura colonial, suprimiendo así las historias de los marginados por servir al arte. En este sentido, es representativa la poesía de Diana Bellessi, Alicia Genovese, y María Negroni. Para nada comprometidas con la figura de ut pictura poesis, que durante tanto tiempo ha ocupado la fantasía de escritores, estas autoras contemporáneas recrean ahora el fenómeno del museo para examinar las diversas percepciones culturales generadas por las mentes metropolitanas.

En un estilo diferente, la novelista Luisa Valenzuela reescribe la tradición noir al situar la acción narrativa en la ciudad de Nueva York donde sigue las aventuras de detectives y escritores. Novela negra con argentinos (1990) se convierte así en una perversión moderna

\footnotetext{
${ }^{10}$ Aunque queda fuera del foco de este ensayo, deberiamos recordar que los hombres latinoamericanos han acudido con regularidad a sus fuentes angloamericanas con un proyecto muy distinto en mente, no necesariamente comprometidos con una estética del género sexual. Ver, por ejemplo, la reciente novela de Ricardo Piglia, La ciudad ausente (1992), donde el Finnegans Wake de James Joyce es objeto de imitación.

${ }^{11}$ En la polémica sobre el papel del artista de vanguardia, es obligado acudir a las observaciones de Beatriz Sarlo (1993).
} 
de la novelística popular; aquí, Valenzuela nos describe a un personaje argentino que se adentra en la ciudad en busca de una identidad autónoma; éste intenta construir una historia propia a pesar de las trabas que ofrece la metrópolis. A su vez, Valenzuela está conscientemente cuestionando la temática de la que dispone el escritor de un país periférico, sobre todo en un momento de crisis económica, donde, parafraseando a Raymond Chandler, "domina el olor a miedo". ${ }^{12}$ La historia de Valenzuela está cargada de elementos relacionados con personajes travestidos que ponen a prueba las definiciones del "otro", de la alienación y del exilio, tal y como se manifiestan en el eje de los intercambios Norte/Sur. Estas transformaciones de la tradición desde la perspectiva del Sur neoliberal también son maneras de producir un heroísmo narrativo diferente, que suponga un desafio a ese tipo de ficción que representa a los latinoamericanos como rehenes cómplices del discurso metropolitano.

A modo de conclusión, enfoco brevemente una novela reciente de Diamela Eltit, en la cual se tratan los poderes de Occidente tal y como son vistos desde la perspectiva de la periferia. En primer lugar, quiero dejar claro que no es la trama de esta novela lo que se opone al paradigma metropolitano, sino el énfasis que Eltit pone en la estética; el arte transforma la manera de pensar sobre el neoliberalismo y sobre la presencia del Norte en el Sur.

Los vigilantes (1994) es una historia de una mujer y de los tipos de vigilancia a los que es sometida por sus vecinos, parientes y, sobre todo, por su hijo y un interlocutor anónimo, que probablemente es el padre del niño. Al final de la obra, la mujer es expulsada de su casa y obligada a vivir en la calle como una vagabunda. La novela consiste en una serie de exclusiones múltiples: el niño es expulsado del colegio y la madre de su casa, mientras que los vecinos persiguen a cualquier individuo que se niegue a cumplir "las leyes de Occidente". Las instituciones de la familia, la escuela y el Estado, rechazan, pues, a los propios individuos que están destinados a acoger.

A diferencia del libro de Isabel Allende, el best-séller Paula (1994), publicado al mismo tiempo que la novela de Eltit, y la cual es un canto a los "valores de familia" y a los vínculos sagrados entre madre e hija, Los vigilantes es un análisis de cómo el arte literario se resiste al régimen neoliberal y de cómo, finalmente, es vencido por éste. Dentro de esta problemática, la estética pertenece al dominio de la madre. Evitando entrar en el mercado y modas de marginalidad que la teoría feminista hace circular a nivel global, Eltit replantea la desintegración de los lazos familiares en la era neoliberal. Aquí no encontramos una idealización de la maternidad, ni se le concede un privilegio especial a la figura del niño, ni tiene lugar una exaltación de la familia latinoamericana que satisfaga los gustos de los lectores extranjeros. Por el contrario, el niño representa a un "otro" que amenaza el arte de la madre. Aun más, el Estado colabora en este acto de agresión.

Eltit se da cuenta de que el Estado no puede articular los intereses de la sociedad civil; pero, debido a la vigilancia constante que ejerce sobre ésta, llega a confundir la separación de espacios públicos y privados, y termina censurando cualquier forma de libre expresión. En este sentido, la periodista argentina Mabel Bellucci expresa su preocupación por la creciente

\footnotetext{
${ }^{12}$ Los paralelismos entre la roman noir y los recientes intentos por parte de novelistas latinoamericanos de escribir bajo la sombra del neoliberalismo, merecen la pena ser explorados. Les agradezco a Jayne Walker y a David Reid la inspiración provocada por la lectura de su ensayo "Cornell Woolrich and the Abandoned City".
} 
pérdida del espacio público: "Lo que se expresa en el hecho observable es que la privacidad del ámbito hogareño se ve invadida por la irrupción del afuera y lo que es peor, que el afuera se convierte en el mecanismo regulador a través del cual depende - casi exclusivamente-el funcionamiento familiar" (1992:8 5). Hasta cierto punto, Los vigilantes corrobora esta opinión, pero Eltit nos muestra que no hay lugar para la nostalgia si se quieren discutir los méritos familiares, no hay un idílico espacio público o privado que respete a niños y adultos. En cambio, la miseria termina invadiendo a todos aquellos sujetos pensantes; el mito la familia latinoamericana se viene abajo.

Eltit comienza dejando fuera todos aquellos elementos simbólicos que se asocian con la mujer: las imágenes domésticas o maternales, la actividad de la escritura como algo sagrado, o la intimidad de la novela epistolar, son reemplazadas por la violencia del Estado. A su vez, Diamela se cuestiona la supervivencia del arte y las condiciones de la creación en una era de vigilancia. Esto queda planteado como un problema dentro de la dinámica entre madre e hijo. Queda claro desde el primer momento que el niño siente rencor hacia la atención que su madre le dedica a los textos; al ser "la única que escribe", ésta debe ser controlada. En comparación con la madre, que es puro discurso sin descripción física alguna y, hasta el final de la novela, sin nombre conocido, el niño es toda corporalidad, necesidad física incesante y se toma a mal las abstracciones de un sistema de escritura que lo reduciría a una figura impresa ("Existo sólo en un conjunto de papeles" 16). Su táctica principal contra la escritora es la oralidad, la expresión brusca y monosilábica que contrasta con las expansivas meditaciones epistolares de la madre: "BAAM, BAAM, me río", pronuncia éste constantemente. El libro también concluirá con un "BAAM" similar, con el que el niño, que controla los acontecimientos de la novela, reirá el último al llevar los sistemas de la escritura a su fin. Las palabras son una pura entidad física en el mundo del niño, previniendo la disolución del yo, pero motivando la destrucción ajena; sus palabras excluyen el concepto de diferencia y aniquilan la privacidad de las acciones creativas. En este sentido, no nos sorprende que el único talento del niño radique en su afición por los números. Por ello, la madre escribe: "Intuyo al interior de su cerebro un proceso altamente numérico que altera mi moderación. Un proceso que le extravía el pensamiento y que desencadena sus irritantes carcajadas" (36). El niño se dedica, pues, a una acumulación que le vincula a "actos de valor universal" (36); así, se enfrenta a la madre, que está aislada en su interés artístico. Los números, la corporalidad y la expresión oral, predominan sobre la escritura: la presencia del niño invade el discurso y la visión de la madre; incluso la naturaleza colabora para suprimir su amor por el arte y la comunidad. El frío hace que los vagabundos mueran congelados y destruye la cultura tal y como la conocemos, al forzar a los individuos a evacuar calles y espacios públicos. De manera similar, las aguas contaminadas prometen una muerte segura a los habitantes locales; la naturaleza está contaminada pero nadie puede detener su avance. Esto promueve el nomadismo en lugar de la cooperación social, e imposibilita el arraigo y la dedicación a la comunidad y al arte. En última instancia, tiene lugar una situación de vigilancia, donde el desarrollo de la diferencia queda predeterminado por leyes tácitas, no escritas. De este modo, la población mundial es dividida en la novela en los irracionales opuestos de Norte y Sur, Este y Oeste, extremos visibles e invisibles, todos ellos determinados arbitrariamente por el ansia monstruosa del cuerpo, desprovisto de pasión y espíritu. 
Al final de la novela, la madre participa en el juego del niño de ordenar unas vasijas vacías, mientras éste inventa un nuevo sistema de defensa fronteriza que separará al amigo del enemigo. "Jamás podrán derribar la simetría en la que conseguimos concentrar nuestras defensas", explica la madre, convirtiendo el juego de fronteras de su hijo en un proyecto estético que desafia la simetría artificial del mercado que divide Norte y Sur(116). Ella se está deshaciendo finalmente de las oposiciones binarias tradicionales para ponerse a pensar en otra forma de comunidad; el arte es invocado ahora para sentar los términos de una nueva alianza. Sin embargo, en las últimas páginas de la obra, también la artista es derrotada; expulsada de su casa, la madre se convierte en una pura entidad física (muerde, se ríe, e imita el primitivo lenguaje del niño) mientras que el niño deambula por las calles heladas, desconcertando a aquéllos que los observan. Al haber perdido todo interés por la razón, ellos se rinden a las fuerzas de la naturaleza, aullando a la luna.

Recordando en cierto modo a Jameson, que declaró - en un controvertido ensayo — la importancia de la escritura alegórica en los intelectuales del Tercer Mundo, DiamelaEltit juega con los límites de este tipo de literatura: por un lado, la novela representa la invasión del paradigma neoliberal impuesto por Occidente; por otro lado, este modo literario fracasa, dejando a sujetos no analizables colgados en los márgenes de las formas narrativas convencionales. Sólo el sentido de la estética consigueganarle terreno a la teoría metropolitana.

\section{Conclusión}

En las hábiles manos de mujeres latinoamericanas tales como las que hemos citado en estas páginas, el tráfico de la cultura como mercancía queda momentáneamente suspendido. Una estética marcada por el género sexual, y una exaltación de la cultura letrada, intervienen en la sociedad de masas y en la economía de mercado. Sin embargo, estas autoras no defienden la autonomía del texto literario, como solía ocurrir en el más puro modelo vanguardista; por el contrario, éstas tienden a moverse hacia el espacio local, hacia una voz fraguada en las tradiciones feministas, siempre dispuestas a esquivar el intercambio Norte/Sur y a reconstruir un área común para el debate. Así, bajo la tutela del neoliberalismo, con sus continuados intentos de suprimir la ambigüedad y fijar todas las categorías de significado en un limitado surtido de fáciles opciones, la estética consigue construir un espacio para el significado elusivo e incierto, crear un terreno para la experimentación que el mercado de compra-venta no puede acomodar. La estética, en definitiva, nos devuelve a las cuestiones de valor — normalmente omitidas en el proyecto neoliberal. Como en el ejemplo del collage fotográfico de Liliana Porter, citado al principio de este ensayo, el discurso femenino interviene aquí no sólo para reordenar los elementos de la sintaxis Norte/Sur, sino también para burlarse de nuestro gusto por la cultura masiva y para eliminar los lugares de la nostalgia. Finalmente, más que ofrecer soluciones absolutas del mismo estilo monumental practicado por el neoliberalismo, las escritoras latinoamericanas de las últimas décadas del siglo veinte vuelven a la ambigüedad y al debate; nos proporcionan un espacio para el diálogo y luchan contra el aislamiento. Por esto se niegan a ocupar un punto único en el mapa hemisférico y proponen a cambio una extensa conversación que trascienda la frontera Norte/Sur.

Traducción de Magdalena Escacena 


\section{Biblografía}

Alarcón, Norma. "The Theoretical Subject(s) of This Bridge Called y Back and AngloAmerican Feminism". Making Face, Making Soul: Haciendo Caras. Gloria Anzaldúa, ed. San Francisco: Aunt Lute, 1990. 356-369.

Behar, Ruth. Translated Woman. Boston: Beacon Press, 1993.

Bellessi, Diana. "Contra una retórica feminista". Feminaria 6 (November, 1990): 10-11.

Bellucci, Mabel. "El feminismo en estos tiempos neoliberales". Feminaria 8 (April, 1992): 3-5.

Beverley, John. Against Literature. Minneapolis: University of Minnesota Press, 1993. Calvera, Leonor. "La cosmovisión feminista". Feminaria 8 (April, 1992): 6-8.

Campra, Rosalba. America Latina: la identidady la máscara. Mexico: Siglo XXI, 1987.

Castañeda, Jorge. Utopia Unarmed. The Latin American Left after the Cold War. New York: Alfred Knopf, 1993.

Castillo, Debra. Talking Back: Toward a Latin American Feminist Literary Criticism. Ithaca: Cornell University Press, 1992.

DeLillo, Don. White Noise. New York: Penguin, 1986.

Donoso, José. Donde van a morir los elefantes. Buenos Aires: Alfaguara, 1995.

Eltit, Diamela. "Las batallas del coronel Robles". Revista de Crítica Cultural 4 (1991): 1921.

Los vigilantes. Santiago de Chile: Sudamericana, 1994.

Ferman, Claudia. Política y posmodernidad: Hacia una lectura de la anti-modernidad en Latinoamérica. Miami: Iberian Studies Institute, 1993.

Fletcher, Lea. "El sexismo lingüístico y su uso acerca de la mujer". Feminaria 1 (June, 1988): 29-32.

Franco, Jean. "Beyond Ethnocentrism: Gender, Power, and the Third World Intelligentsia". Marxism and the Interpretation of Culture. Cary Nelson and Lawrence Grossberg, eds. Urbana: University of Illinois Press, 1988. 503-515.

Kaminsky, Amy. Reading the Body Politic: Feminist Criticism and Latin American Women Writers. Minneapolis: University of Minnesota Press, 1993.

Kirkpatrick, Gwen. "El feminismo en tiempos de cólera". Revista de Crítica Literaria Latinoamericana 21/42 (1995): 45-55.

Maffia, Diana. "Lógica, sexualidad y política". Feminaria 12 (May, 1994): 10-11.

Maglie, Graciela. "Bajo sospecha". Feminaria 5 (April, 1990): 29-31.

Mercado, Tununa. "Atravesar el espejo". Feminaria 3 (April, 1989) 21-22.

Mohanty, S. P. "Us and Them: On the Philosophical Bases of Political Criticism". Yale Journal of Criticism 2/21-31 (1989).

Monzón, Isabel. "Psicoanálisis y mujer". Feminaria 8 (April, 1992): 19-23.

Moreiras, Alberto. "Postdictadura y reforma del pensamiento". Revista de Crítica Cultural 7 (1993): 26-35.

Negroni, María. Ciudad gótica. Rosario-Buenos Aires: Bajo la Luna Nueva, 1994.

Perlongher, Néstor. "Los devenires minoritarios". Revista de Crítica Cultural 4 (1991): 13-18.

Piglia, Ricardo. La ciudad ausente. Buenos Aires: Sudamericana, 1992. 
"Sarmiento the Writer". Sarmiento, Author of a Nation. Tulio Halperín Donghi, I. Jaksic, G. Kirkpatrick, F. Masiello, eds. Berkeley: University of California Press, 1994. 127-144.

Porter, Carolyn. "What we Know that We Don't Know: Remapping American Literary Studies". American Literary History 6/3 (1994) 467-526.

Richard, Nelly. "Latinoamérica y la post-modernidad". Revista de Crítica Cultura 3/1519 (1991). Masculino/Femenino. Santiago de Chile: Francisco Zegers, 1993.

Safranchick, Graciela. Kadish. Rosario-Buenos Aires: Bajo la luna nueva, 1993.

Sarlo, Beatriz. "Arcaicos o marginales? Situación de lso intelectuales en el fin de siglo". Punto de vista 16/47 (1993): 1-5.

Sheper-Hughes, Nancy. Death Without Weeping. Berkeley: University of California Press, 1992.

Stephen, Lynn, (ed.). Maria Teresa Tula: Hear My Testimony. Boston: South End Press, 1994.

Thénon. Susana. Ova completa. Buenos Aires: Sudamericana, 1987.

Valenzuela, Luisa. Novela negra con argentinos. Hanover: Ediciones del Norte, 1990.

Walker, Jayne and David Reid. "Cornell Woolrich and the Abandoned City" Shades of Noir. Joan Copec, ed. London: Verso, 1993. 57-96.

Yúdice, George. "Estudios culturales y sociedad civil". Revista de Crítica Cultural 8 (1994): 44-53. 